\title{
Finanças públicas e evolução recente da noção de disciplina fiscal *
}

\author{
Neide César Vargas **
}

\begin{abstract}
Resumo
O objetivo deste artigo é evidenciar a perspectiva de disciplina fiscal atualmente dominante, visando desnaturalizar essa questão tão dogmatizada pelo mainstream. O delineamento de dois contextos institucionais no âmbito da história recente do capitalismo mundial, segundo a concepção hegemônica no que tange à disciplina fiscal, permite identificar um primeiro contexto em que prevalece uma visão de disciplina fiscal frouxa e um segundo, no qual predomina a visão de disciplina fiscal forte, evidenciando o caráter historicamente datado dessa noção e a sua particularidade no contexto atual.
\end{abstract}

Palavras-chave: Finanças públicas; Disciplina fiscal; Política fiscal; Economia do setor público; Estado rentista.

\section{Abstract \\ Public finance and the recent evolution of the concept of fiscal discipline}

The aim of this essay is to highlight the currently dominant perspective of fiscal discipline in order to denaturalize this question treated dogmatically by mainstream. The design of the two institutional contexts in the recent history of world capitalism, according to the hegemonic conception of fiscal discipline, identify a first context of soft budget constraint and a second of hard budget constraint, revealing the historically dated character of this notion and its particularity in the current context.

Keywords: Public finance; Fiscal discipline; Fiscal policy; Economics of the public sector; Rentier state.

JEL H00, H30, H60.

\section{Introdução}

Nas últimas décadas, a noção de disciplina fiscal vem assumindo um papel central nas visões dominantes a respeito das Finanças Públicas ${ }^{1}$. A austeridade fiscal aparece como uma exigência inequívoca no âmbito das políticas públicas e mesmo do senso comum. O controle do endividamento público, a busca de redução ou, no mínimo, de estabilização dos níveis da dívida pública, e a ideia da necessidade de

* Trabalho recebido em 3 de maio de 2010 e aprovado em 18 de setembro de 2011. Sintetiza algumas das conclusões presentes em Vargas (2006).

${ }^{* *}$ Professora Associado I e pesquisadora do Departamento de Economia da Universidade Federal do Espírito Santo, Vitória, ES, Brasil. E-mail: neide.vargas@uol.com.br..

(1) Um survey acerca das principais vertentes da Macroeconomia mainstream encontra-se em Lopreato (2006). Especificamente sobre a perspectiva de austeridade fiscal do Hard Budget Constraint, ver Kornai (1986) e Kornai et al. (2004). Uma das abordagens seminais de austeridade fiscal pela Escolha Pública focada especificamente na crítica à Keynes encontra-se em Buchanan e Wagner (1977). 
geração recorrente de superávits fiscais para alcançar tais objetivos encontram-se relativamente disseminados pelo mundo e mesmo no Brasil. A questão do porquê restringir a atuação do Estado soa como óbvia para o pensamento que se tornou hegemônico tanto no campo teórico quanto prático. Verificou-se uma naturalização da noção de disciplina fiscal, a qual alimenta a submissão do Estado a crescentes restrições fiscais e, em última instância, aos interesses da valorização de capital, notadamente em sua forma de capital fictício.

Entender de maneira crítica esse contexto requer estabelecer alguns vínculos básicos entre tais concepções: a natureza da disciplina fiscal e as grandes transformações sofridas pelo Estado e pela Economia no capitalismo mundial. Essas transformações mais gerais desencadearam mudanças nos Estados-Nação, alçando a questão da restrição fiscal e financeira do setor público a um papel de destaque. É necessário evidenciar o aspecto histórico dessa perspectiva que passa a nortear o trato das Finanças Públicas e traz consigo a centralidade e a complexificação do conceito de disciplina fiscal.

Sob a ótica dos interesses dos detentores de crédito, seus maiores beneficiários no âmbito da ordem atual, a disciplina fiscal pode ser analisada em dois grandes contextos institucionais: o primeiro, que vai do pós segunda guerra até fins dos anos 70, etapa na qual a perspectiva corrente de disciplina fiscal é considerada frouxa, e o segundo, que parte do final da primeira etapa até os dias atuais, no qual se dissemina a noção de disciplina fiscal forte ${ }^{2}$.

O objetivo deste artigo é, por meio do delineamento desses dois contextos, evidenciar a perspectiva atualmente dominante de disciplina fiscal, a visão de Estado, de déficit e de dívida pública que lhe são correlatas, visando desnaturalizar essa questão tão dogmatizada pelo mainstream.

Este artigo está dividido em dois itens: o primeiro destaca o contexto institucional de disciplina fiscal fraca (1) e o segundo aborda o contexto recente de disciplina fiscal forte (2). Em ambos contextos, as visões teóricas prevalecentes, relacionadas à atuação do Estado, à concepção hegemônica acerca do déficit e dívida públicos, bem como à visão de disciplina fiscal são evidenciadas em subitens específicos (1.1 e 2.1). No segundo contexto, agregou-se também o subitem (2.2), que apresenta as novas concepções de disciplina fiscal forte desde a matriz teórica da Economia do Setor Público (Escolha Pública e Nova Economia Institucional). Esta última matriz é, na maioria das vezes, desconsiderada nas discussões heterodoxas acerca da questão fiscal. Por fim, o artigo apresenta algumas notas, à guisa de conclusão.

(2) Kornai $(1986,2004)$ apresentam, de maneira estilizada, dois contextos segundo a ótica da disciplina fiscal. Este é um autor muito citado pelo mainstream, tendo introduzido a ideia de restrição orçamentária forte (hard budget constraint). 


\section{Primeiro contexto: a disciplina fiscal fraca}

A noção de disciplina fiscal pode ser analisada num contexto que se configurou no pós segunda guerra sob a pressão de um ambiente político prévio extremamente conturbado. A disseminação de questionamentos sobre as virtudes da economia de mercado e do laissez-faire caracterizava aquele ambiente, reunindo desde o descontentamento generalizado na Europa com os efeitos das guerras mundiais, a grande depressão e os pavores do nazifascismo até a ameaça de adesão ao comunismo por parte dos países fragilizados. O contexto configurado englobava, no plano do Estado, um padrão de articulação social que se refletia na esfera pública através da montagem do Welfare State nos principais países desenvolvidos. A ampla e crescente atuação do Estado que passou a se verificar tanto na esfera econômica quanto social contribuiu para sustentar uma longa fase de prosperidade, com grande liberdade para que os vários Estados Nacionais conduzissem as suas políticas econômicas e de desenvolvimento, inclusive os países da periferia mundial (Belluzzo apud Affonso, 2003, p. 11).

O modelo de acumulação de capital então prevalecente, irradiado a partir da economia norte-americana, promovia internamente, na esfera macroeconômica, o que Belluzzo (2000, p. 100) denomina de uma "Economia da Demanda Efetiva". Esse modelo incorporava, como um de seus elementos de dinamismo, o Gasto Público, podendo ensejar situações de déficit fiscal. Desde as experiências concretas dos anos 30, nas quais vários países obtiveram resultados favoráveis no combate à recessão a partir do uso do gasto público, o déficit público tornou-se uma alternativa aos governos que se viam politicamente pressionados por quadros recessivos e de elevado desemprego ${ }^{3}$.

O Estado passou gradualmente a ser visto como um ente afirmativo, capaz de adotar um comportamento ativo no âmbito da dinâmica econômica e social, promovendo, a partir de políticas públicas, ações indutoras do bem-estar econômico e social. A pressão política para que o Estado assumisse a posição de estabilizador de expectativas redundou numa ordem na qual se destacou como ente fundamental, tornando possível, sempre que se considerava necessário, recorrer a políticas de déficit público financiadas de maneira relevante por meio do crédito. $\mathrm{O}$ ambiente institucional que se criou foi capaz de garantir crédito barato e dirigido à acumulação produtiva, promovendo níveis de crescimento econômico relevantes nas principais economias industriais com manutenção do pleno emprego e da inflação em patamares rastejantes ${ }^{4}$.

(3) Sobre algumas experiências de recuperação econômica com atuação do Estado no pós-guerra, ver Bleaney (1985).

(4) Acerca dos chamados anos gloriosos, ver Van Der Wee (1987), Zysman (1983), Glyn et al. (1990) e Guttmann (1994). 
Com o déficit e o gasto públicos alçados à estratégia de atuação governamental mais relevante, a política fiscal se transformou no instrumento por excelência dessa atuação. A tendência era a adoção de uma política fiscal flexível, voltada para a ampliação do gasto público com a aceitação social do déficit orçamentário enquanto instrumento de promoção do pleno emprego, do crescimento econômico e da equidade.

O ambiente de política fiscal ativa conjugou-se ao de uma política monetária acomodatícia, voltada para sancionar as decisões de gasto das empresas, das famílias e do governo. O Estado compartimentalizava e regulava com severidade a atuação das instituições financeiras com o controle dos fluxos de capital especulativo. No plano interno aos países, a restrição à atuação dessas instituições passou a predominar com amplo direcionamento da oferta de crédito às aplicações produtivas. $\mathrm{O}$ crédito era disponibilizado às corporações, às famílias e aos governos a taxas de juros baixas e estáveis (Belluzzo, 2000, p. 100-101).

No plano internacional, num quadro de guerra fria, verificou-se a disseminação do modelo de acumulação norte-americano, estabelecendo-se uma relação de complementaridade entre essa economia hegemônica, os principais países industriais e mesmo parcela da periferia mundial. A relativa complementaridade entre as nações configurava-se, na esfera produtiva, através da gradual absorção, pelo mercado interno norte-americano, das exportações de outros países. Também provinham desse país, e posteriormente dos países europeus, fluxos de investimento direto vinculados à expansão de empresas transnacionais, disseminando seu padrão de acumulação pelo mundo.

O crédito internacional proveniente das economias mais desenvolvidas, em especial dos EUA, também se dirigia, em caráter prioritário, para a acumulação produtiva, financiando a expansão econômica em escala mundial. Nesse contexto, o banco central norte-americano atuava, na prática, como um emprestador de última instância para os demais países. Esse direcionamento dos fluxos de capital para investimento direto ou para crédito ao investimento direto contribuía para garantir o regime de câmbio fixo então vigente e para o quadro geral de promoção da acumulação produtiva e de forte atuação do Estado.

As taxas de juros e de câmbio relativamente estáveis e orientadas pelos governos de forma a estimular a acumulação produtiva levaram a uma ampla expansão da tomada de crédito voltado para a esfera da produção. O contexto institucional vigente estimulava a captação de recursos da parte de todos os agentes, sendo o lado devedor o mais favorecido das relações de crédito no âmbito social como um todo, potencializando a geração de riqueza produtiva (Belluzzo, 2000, p. 100). 
Frente à relevante atuação do Estado, direta ou indiretamente, à ampla utilização de políticas de demanda efetiva e do crédito, bem como às políticas de desenvolvimento nacionais de forma disseminada em âmbito mundial, a ideia de austeridade fiscal, de orçamento equilibrado e seus congêneres perdeu espaço para visões teóricas mais ajustadas àquela situação. A disciplina fiscal foi relegada a questão de segunda ordem tendo em vista o peso pouco relevante do déficit e da dívida pública para os países mais avançados, em especial até meados dos anos 60 . Ante esse contexto institucional específico, demandaram-se teorias na Economia mais compatíveis com o crescente papel do Estado e que abrangessem o governo, o gasto e déficit públicos, bem como as suas funções.

\subsection{Visões teóricas da atuação do governo, do déficit, da dívida pública e a disciplina fiscal fraca}

A arquitetura política do ambiente gestado nessa primeira etapa de predomínio de políticas econômicas e sociais ativas, ao alçar o Estado a um papel fundamental, requereu teorias que justificassem essa atuação. Esse contexto ensejou o nascimento da Macroeconomia moderna, bem como o da Economia do Setor Público. Keynes tornou-se um referencial teórico fundamental no que tange à questão da atuação ativa do Estado nas economias capitalistas. Mas é a Síntese Neoclássica, em especial a abordagem de Samuelson, que forneceu as bases efetivas para a justificação e a ampliação da presença do Estado na sociedade daquela ocasião. Esse amplo movimento teórico, que se tornou consensual e disseminado a partir dos anos 50, resultou de simplificações da teoria de Keynes. Filtrou-a de seus elementos centrais, especialmente a noção de incerteza distinta de risco e da ocorrência do desemprego involuntário, reintroduziu o paradigma do equilíbrio e tratou a questão do desemprego a partir da noção de rigidez no mercado de trabalho (Affonso, 2003, p. 12), compatibilizando a visão teórica preexistente com a de Keynes por meio de modelos matemáticos, IS-LM, nos quais as expectativas dos agentes estavam totalmente ausentes 5 .

Tais simplificações alteraram de maneira substancial o pensamento original de Keynes ${ }^{6}$ ao mesmo tempo que ensejaram uma generalização da utilização de modelos keynesianos no âmbito dos países, disseminando-os como um instrumento hegemônico de condução da política econômica. A política fiscal foi alçada, por essa perspectiva dominante, à esfera preferencial de observação teórica e ao papel de política econômica por excelência, com a tarefa de gerar, através do déficit público,

(5) Criado nos anos 30 e início dos anos 40 por John Hicks e Alvin Hansen, conforme Blanchard (2004).

(6) A visão original de Keynes está longe de defender o déficit público como ferramenta de atuação governamental de uso indiscriminado e de resultados automáticos como tende a ocorrer na Síntese Neoclássica. Nesta, o déficit público funciona como um mecanismo de geração de demanda efetiva nas situações de depressão cíclica, e não como um instrumento de uso continuado (Keynes, 1985). 
o pleno emprego, sendo teorizada sob os supostos vigentes de taxas de câmbio fixo e taxas de juros baixas e estáveis. A noção da curva de Phillips, que se agregou a esse instrumental, difundia a ideia de que era necessário aceitar certa inflação para se reduzir o desemprego. Sob a leitura desse keynesianismo "bastardo", são estabelecidas as justificativas teóricas de políticas econômicas ativas pautadas em mecanismos anticíclicos automáticos voltados para suavizar as crises e efetuar transferências de renda a segmentos socialmente fragilizados cujo cerne estava dado pela política fiscal.

No debate acadêmico de então prevalecia o embate dos autores da Síntese Neoclássica versus Monetaristas, cujo foco acerca da disciplina fiscal se concentrava "nos efeitos do déficit público sobre a inflação e o balanço de pagamentos (os chamados déficits gêmeos) e, de outro, no impacto do gasto público na demanda agregada e nos investimentos privados em decorrência do crowding out" (Lopreato, 2006, p. 2).

A Economia do Setor Público é um dos desdobramentos teóricos da Síntese Neoclássica, incorporando, sob seu viés, a perspectiva keynesiana. Em ambas, o Estado é reduzido à noção de governo, sendo tratado de maneira a-histórica e separada da política. À Economia do Setor Público caberia estudar as situações nas quais o governo se torna necessário, provendo o que Samuelson chamou de Bens Públicos. Ela se configurou, em especial, a partir de um quadro conceitual que conjugava as teorias de Samuelson, Musgrave e Arrow (Oates, 2005, p. 350), sendo a atuação governamental entendida como complemento às situações em que o mercado falhava.

Musgrave e Musgrave (1980) agregaram aspectos adicionais à visão de Samuelson, evidenciando que a ação do governo se tornava necessária para "corrigir" e "suplementar" o mercado. Amplamente influenciados pela Síntese Neoclássica, esses últimos autores definem que as funções do governo deveriam ir além da alocação de bens e serviços. Envolveriam também a atuação na esfera da estabilização, na forma de políticas de promoção de pleno emprego sem impacto inflacionário e na da distribuição pautada na persecução de padrões de equidade considerados socialmente aceitáveis a partir da adoção de políticas distributivas. Essa visão das funções do governo relacionadas de forma fundamental à esfera fiscal passaria a configurar a abordagem posteriormente difundida pelo mainstream de que cabe ao governo exercer funções na esfera Alocativa, da Estabilização e da Distribuição, tendo a política fiscal ativa como um importante instrumento.

Kenneth Arrow incorporou, nos anos 70, outro avanço teórico de destaque na Economia do Setor Público com a distinção de papéis dos setores público e privado. Pautado no equilíbrio geral walrasiano, utilizava, como sustentáculos teóricos, a 
noção de ótimo de Pareto e a racionalidade maximizante dos agentes econômicos. $\mathrm{O}$ conceito de falha de mercado é desenvolvido e tipificado, passando a se difundir e fornecendo a justificativa teórica para uma atuação governamental em amplas esferas (Affonso, 2003, p. 13).

A teorização do governo pela Economia do Setor Público assentava-se numa visão que prescindia da sua dimensão política, bem como a inserção em um contexto histórico particular. Aplicável a qualquer país, essa teorização identificava no governo um ente interventor voltado para corrigir as falhas de mercado, uma caixa preta sobre a qual não se teorizava. Era um deus ex machina capaz de decidir e produzir os bens e serviços públicos que não podiam ser produzidos pelo mercado.

A Economia do Setor Público consolidou-se como uma área de conhecimento voltada para o estudo das falhas de mercado e das funções do governo. Nela, a ideia de disciplina fiscal tinha pouco destaque, tal como na Macroeconomia da Síntese Neoclássica. O momento histórico e a própria perspectiva teórica hegemônica justificavam a ocorrência de déficits públicos, o uso do crédito e da dívida para financiá-los. Se existiam restrições, elas eram efetivamente voltadas para o campo monetário/financeiro e para dirigir os recursos públicos e privados ao gasto produtivo, orientando os fluxos internacionais de capitais, resultando em economias cujo funcionamento era relativamente fechado e com ampla participação do Estado.

A ideia de falha de mercado justificava amplas intervenções do Estado, coadunando-se com a expansão da atuação estatal tanto na forma do Welfare State quanto nos Estados Desenvolvimentistas da periferia mundial. No campo fiscal, chancelava uma concepção de flexibilidade fiscal para uma atuação governamental cada vez mais abrangente.

A concepção de disciplina fiscal prevalecente nesse contexto era frouxa, com facilidade para a tomada de crédito pelos diversos agentes. $\mathrm{O}$ baixo risco ao qual os tomadores de recursos estavam submetidos ampliava os níveis de investimentos globais e potencializava o crescimento econômico. No caso do governo, essa facilidade possibilitava os déficits orçamentários, borrando os limites entre a esfera fiscal e financeira de sua atuação. Não obstante, a perda de dinamismo do modelo de acumulação nele implícito em meados dos anos 60 gradualmente abriu espaços para a instauração de um novo contexto institucional.

\section{Segundo contexto: a disciplina fiscal forte}

A perspectiva de flexibilidade no trato com a questão orçamentária foi prevalecente no Estado capitalista até a perda de funcionalidade do padrão de acumulação predominante desde o pós segunda guerra. Isso se deu em meados dos anos 60 , com a intensificação de seus efeitos deletérios nos anos 70, especialmente 
na forma de estagnação, inflação e crescimento da dívida pública (Coutinho; Belluzzo, 1998, p. 11). Com a corrosão do poder financeiro do dólar, os controles sobre os fluxos de capital passaram a se tornar sem efeito, com fugas de capital da economia hegemônica para os mercados de eurodólares, crise e estagnação nas economias centrais. A ruptura no regime de câmbio de Bretton Woods desencadeou a liberalização cambial nas economias de maior peso, a qual, somada aos dois choques de preço do petróleo ao longo da década de 70, resultou em grande turbulência no funcionamento das esferas pública e privada mundiais. A decisão do governo norte-americano de elevar de maneira significativa a taxa de juros, em 1979, trouxe implicações decisivas sobre essa realidade, tornando-a insustentável. Ante o contexto econômico desfavorável, passaram a tomar corpo as ideias conservadoras de que a crise mundial era consequência das políticas de Bem-Estar Social e keynesianas até então praticadas (Fiori, 1997, p. 116). Vitoriosas no plano político, nos EUA, tais ideias resultaram num conjunto de reformas neoliberais do Estado, em diferentes planos, inicialmente com políticas fiscal e monetária restritivas, com ampla desregulamentação dos mercados e privatizações, culminando numa nova ordem internacional ${ }^{7}$, trazendo consigo também uma nova concepção de disciplina fiscal.

As políticas econômicas ortodoxas tenderam a se disseminar pelos países mais desenvolvidos, especialmente nos anos 80, influenciadas pela política macroeconômica norte-americana restritiva aplicada no início daquela década, levando a uma forte recessão mundial. Ocorreram repercussões negativas sobre os resultados fiscais e as dívidas públicas dos diferentes governos, com ampliação do componente de juros e ascensão vertiginosa do estoque de dívida. A retomada do crescimento dos EUA em 1983, pautada numa política fiscal ativa e assentada na ampliação da dívida em títulos públicos, inaugurou um período de recuperação do crescimento mundial $^{8}$ e ao mesmo tempo um novo regime de financiamento das demandas públicas e privadas de liquidez. Nos demais países, manteve-se a pressão para a continuidade ou adoção de políticas monetária e fiscais restritivas.

No plano estrutural, o movimento de desregulamentação então desencadeado envolveu o desmonte das restrições institucionais gerais que já havia sido iniciado no mercado de câmbio desde os anos 70 e avançou pelo mercado de bônus privados e públicos ao longo dos anos 80 , atingindo também o mercado de ações, correspondendo, no conceito de Chesnais, ao processo de mundialização financeira (Chesnais, 1998, p. 12).

No que tange ao Estado, o déficit e dívida públicos norte-americanos assumiram um papel de base e motor do processo de globalização financeira, ou,

(7) Sobre a nova ordem internacional e a retomada da hegemonia norte-americana, ver Tavares (1997) e Fiori (1997).

(8) Sobre a questão da recuperação dos EUA a partir de 1983, ver Baer (1994, p. 43), Cline (1989, p. 53-57) e Marris (1987, p. 42-43). 
nos termos de Braga (2000, p. 279), a base da "financeirização" da riqueza, dadas as características dos mercados de títulos públicos ${ }^{9}$. Ao longo da década de 80 , grande parte da liquidez internacional foi absorvida por essa economia na forma de títulos, monetizando, de maneira geométrica, a dívida pública norte-americana.

Os governos dos principais países industrializados do mundo aderiram a essa nova ordem, interessados no financiamento de seus déficits e dívida crescentes. A liberalização e a internacionalização do mercado de bônus redefiniram as formas desse financiamento. Estabeleceu-se uma correspondência entre o aumento dos déficits públicos dos países industrializados e o crescimento potencial do capital globalizado e liberalizado.

$\mathrm{Na}$ Macroeconomia adotada pelos governos, passaram a prevalecer os interesses do lado credor/detentor de créditos e da riqueza, com a lógica financeirizada pressionando para a adoção de uma política econômica pautada em taxas de juros reais elevadas e inflação extremamente baixa, além do compromisso inequívoco dos governos com o pagamento dos juros da dívida pública.

Em termos gerais, a política monetária traduziu-se no principal instrumento de regulação macroeconômica, e a política fiscal foi sendo gradativamente relegada a uma função passiva e controlada. A política fiscal perdeu a autonomia relativa e, subordinada à esfera financeira, foi submetida a uma crescente disciplina. A prioridade absoluta dos governos passou a ser a luta contra a inflação e a estabilidade monetária ${ }^{10}$, perdendo importância política, como objetivo governamental, a questão do emprego, do investimento e do crescimento. A política fiscal tornouse, desde então, refém de um mecanismo que confere crescente importância ao Estado no sentido de ser avalista de última instância do processo de valorização financeira do capital. Esse novo padrão de atuação pública se insere num contexto de baixo crescimento do investimento e do produto, com redução das principais bases de cobrança de tributos - a renda de assalariados, os lucros provenientes da esfera produtiva e as transações vinculadas ao processo produtivo.

A nova ordem, tanto no plano de reformas estruturais voltadas para a desregulamentação e a redução do tamanho do Estado quanto no plano da política econômica, resultou num quadro mundial de finanças desreguladas, com ampla liberalização dos fluxos de capitais. A crescente liberalização privada correspondeu ao surgimento de fortes restrições fiscais e financeiras na esfera pública, essas últimas cuja intensidade seria equivalente ao poder de determinação de cada Estado-Nação no quadro de forças internacionais.

(9) Principalmente pelas virtudes de ser o mercado mais profundo e mais líquido.

(10) Conforme comprova Plihon (1995) para os países europeus. 
Num contexto institucional em que o foco se encontra na preservação da riqueza, e não na sua geração, disseminou-se uma nova visão de Estado, de dívida e do déficit, com a prevalência da questão da disciplina fiscal. Tal visão sustentou-se, no âmbito dos governos, no paulatino desmonte da institucionalidade regulatória estatal, típica do Estado de Bem-Estar Social, na intensificação dos processos de privatizações, no desmonte das redes de proteção social e na desregulamentação pública da atividade econômica. O mercado passou a ser visto como a esfera capaz de promover a eficiência e a concorrência (Affonso, 2003, p. 83).

$\mathrm{O}$ aprofundamento e avanço das reformas e políticas neoliberais em termos mundiais nos anos 90, com a incorporação dos então chamados "mercados emergentes", ampliou os níveis de instabilidade global, levando a um ambiente internacional extremamente volátil, de crescente instabilidade das taxas de câmbio e das taxas de juros, com tendência à ocorrência de choques e sobressaltos financeiros. As crises financeiras verificadas desde meados da década atingiram em especial os países com maior vulnerabilidade em termos dos seus balanços de pagamentos, trazendo riscos de perdas em escala global.

A explicitação dos riscos dessa nova ordem internacional fez crescer, entre os seus próprios beneficiários, a preocupação de que os governos mais endividados passassem a atender de maneira inequívoca aos requisitos orçamentários e financeiros mais rigorosos, garantidos não apenas por medidas de curto prazo, mas também por um comprometimento desses países com as dívidas prévias e com um regime de austeridade fiscal. Notadamente, isso se verificou em países de maior risco, sujeitos a problemas estruturais e dependentes de ajuda de instituições financeiras internacionais e do Fundo Monetário Internacional, e mais suscetíveis a pressões.

Desde as crises dos anos 90, o enquadramento prático da política fiscal às restrições macroeconômicas tornou-se mais premente, e as mudanças exigidas demandaram um controle mais estrito do Estado. A disciplina fiscal colocou-se como uma concepção dominante, passando a assumir níveis cada vez mais específicos, capazes de promover a austeridade em todas as esferas da atuação governamental, complexificando-se gradualmente. Os ajustes fiscais estruturais passaram a ser priorizados, requerendo mudanças institucionais continuadas para que se concretizassem. Nos países que não detinham moedas fortes e estavam às voltas com elevados níveis de endividamento, as pressões sobre a política fiscal impingiam a necessidade de geração de elevados e recorrentes superávits primários.

Nesse contexto institucional, novas visões teóricas acerca do déficit e da dívida passaram a ser incorporadas no âmbito da política econômica desses países, assentadas em perspectivas negativas da atuação governamental, a serem discutidas a seguir. 


\subsection{Visões teóricas da atuação do governo, do déficit, da dívida pública e a disciplina fiscal forte}

O questionamento radical das políticas keynesianas e do uso de políticas de déficit público como instrumento de promoção do investimento e do crescimento da economia foi empreendido pela visão das expectativas racionais, amplamente hegemônica na Macroeconomia mainstream desde os anos 80. Para além de Friedman e do monetarismo, que consideravam as políticas econômicas ativas mais um mal do que um bem, Lucas afirmava que as mesmas só poderiam fazer mal. Seu argumento é que sendo os agentes econômicos racionais, eles incorporariam políticas monetárias previsíveis às suas expectativas, anulando seu efeito, restando ao governo adotar políticas aleatórias, o que, por outro lado, geraria efeitos instabilizadores sobre a produção. Isso leva Lucas a concluir que "[...] qualquer política monetária que vise estabilizar o ciclo econômico seria ou ineficaz ou contraproducente" (Krugman apud Affonso, 2003, p. 37-38)

Os autores das expectativas racionais levantaram objeções acerca dos efeitos benéficos de políticas econômicas ativas, tanto no curto quanto no longo prazo, preconizando o abandono de políticas discricionárias e sugerindo a adoção de regras como a melhor forma de estabelecer a relação do governo com o mercado. Segundo essa visão, além de desnecessário para promover o crescimento e a renda, melhor providos pelo mercado e pelo setor privado, o governo requeria um controle estrito através de regras. Essa teoria rompeu com a visão relativamente positiva do Estado e do governo na Macroeconomia, passando a vê-los como agentes de distúrbio.

Em termos mais específicos, a fundamentação da Macroeconomia mainstream, desde o princípio da expectativa racional, implicou a aceitação da concepção de que se o governo muda as regras do jogo econômico isto desencadeia alterações no comportamento dos agentes privados em conformidade com as novas condições vigentes. $\mathrm{O}$ relativo consenso que se formou em torno dessa concepção passou a requerer que as autoridades econômicas levassem em conta o impacto das suas decisões nas expectativas dos agentes, as quais se formariam a partir de avaliações do "regime de política econômica e do ambiente econômico esperados, com respostas diferentes conforme a leitura da política vigente e a confiança na continuidade da estratégia adotada" (Lopreato, 2006, p. 4).

Sob essa nova perspectiva teórica hegemônica, a disciplina fiscal é alçada à posição de sustentáculo da política econômica, que também deveria ter no seu cerne a credibilidade dos agentes nas políticas que o governo adota; credibilidade, essa, a ser construída por meio de medidas coerentes e estruturais voltadas para o estabelecimento de um novo regime de política econômica. 
Fundamenta a noção de disciplina fiscal forte, o conceito de sustentabilidade da dívida pública, o qual busca discutir a capacidade de pagamento da mesma à luz de determinada situação macroeconômica, bifurcando-se em duas abordagens mais importantes ${ }^{11}$ : uma, pautada na restrição orçamentária intertemporal do setor público e outra, na sustentabilidade do crescimento da dívida pública.

Deve-se destacar que a noção de sustentabilidade financeira intertemporal é pessimista, buscando prevenir a situação mais desfavorável aos detentores dos recursos investidos, ou seja, na qual a taxa de juros real é superior ao crescimento real do produto. Ela impõe que, no longo prazo, a taxa de crescimento da dívida pública seja menor que a taxa de juros, o que é compatível com oscilações na relação dívida/PIB ao longo do tempo. É, portanto, relevante a comparação entre a capacidade dos governos de geração, no tempo, de fluxos de superávits primários, descontados em valor presente pela diferença entre a taxa real de juros e a taxa de crescimento da economia e o nível inicial da dívida. Busca-se que os níveis desses superávits cubram a parcela de juros reais não financiada pelo imposto inflacionário ou pelo crescimento do produto. Considera-se que o serviço da dívida não deve ser indefinidamente pago com nova dívida e que os níveis de superávit devem ser ajustados, no caso de situações que capitalizam a dívida, ao invés de reduzi-la, ampliando os riscos para os credores ${ }^{12}$. Para determinada vertente, o foco tende a se deslocar para a capacidade de elevação sustentável da carga tributária pelo governo de forma a gerar os superávits necessários ${ }^{13}$.

A partir dessas concepções de sustentabilidade, são derivadas novas formas de mensurar os impactos da política fiscal, definindo meios para seus desdobramentos ao longo do tempo. A noção de resultado fiscal e de Necessidade de Financiamento do Setor Público ou medidas diversas de déficit público, indicadores usuais de Finanças Públicas, passaram a ser consideradas insuficientes para caracterizar uma situação fiscal de determinado governo. Sob o foco das expectativas racionais, a expectativa de sustentabilidade financeira intertemporal da política fiscal é alçada a um papel nodal ${ }^{14}$, articulando essa esfera à questão do endividamento e inserindo-a numa moldura financeira. A persecução de novos indicadores quantitativos para

(11) Conforme os autores citados e classificados por Guardia (1999, p. 22), segundo as vertentes que estudam a restrição orçamentária intertemporal do setor público (Barro; Sargent; Wallace) e as que estudam a sustentabilidade do crescimento da dívida pública (Domar; Barro; Spaventa; Blanchard).

(12) Essa noção de sustentabilidade é classificada por Rocha (2004) como sendo a abordagem do valor presente.

(13) Nas controvérsias acerca dos efeitos de uma política de geração de superávits primários sobre as variáveis envolvidas na política de ajuste fiscal, pode-se perceber que existem diferentes posições no que tange ao perfil adequado, conforme destaca Rocha e Giuberti (2005). A concepção de sustentabilidade de Guardia (1999), segundo a qual a geração de superávits remete diretamente ao aumento da carga tributária, é a que prevaleceu no Brasil durante o governo Fernando Henrique Cardoso.

(14) Lopreato (2004) discute explicitamente esse aspecto de novidade na visão do papel da política fiscal, focando sua abordagem na atuação do FMI. 
a avaliação da política fiscal manifesta, de forma explícita, a estratégia de buscar meios práticos para efetivamente controlá-la.

Recursos econométricos cada vez mais sofisticados passaram a moldar essa busca de indicadores intertemporais de política fiscal, incorporando a nova perspectiva de restrição. Isso resultou na construção de indicadores da capacidade de pagamento da dívida pública dos diversos países, viabilizando um controle estrito e continuado das políticas fiscais dos mesmos à luz de diferentes situações macroeconômicas, tendo a sustentabilidade financeira da dívida pública como base.

Segundo Lopreato (2006, p. 26), a ideia de sustentabilidade da dívida incorporou a visão prospectiva à análise da situação das contas públicas, bem como requereu o comprometimento dos governos com a garantia dos ganhos esperados dos investidores privados. Para o autor, a teorização da Macroeconomia mainstream legitimou esse compromisso segundo duas frentes de análise: a primeira, assentada na "idéia de solvência da dívida pública como parte do rol de ativos usados como espaço de valorização dos capitais"; a segunda, que "estabeleceu as articulações com as outras variáveis determinantes dos ganhos esperados dos investidores". Essa última engloba análises que discutem as interações entre política monetária e política fiscal (Lopreato, 2006, p. 12, 20-22, 26), vertentes que atrelam medidas de austeridade fiscal e combate aos déficits fiscais prospectivos como estratégia de prevenção de crises cambiais (Lopreato, 2006, p. 17-19), além de abordagens que relacionam a política fiscal, as taxas de juros, os fluxos de capital e prêmios de risco. Em todas essas frentes de análise teórica, atribui-se papel central à adoção de medidas de disciplina fiscal forte.

Sob um regime fiscal pautado em restrição orçamentária forte, tendem a ser exigidos crescentes detalhamentos no sentido de compromisso com medidas de ajuste fiscal estrutural, com análises feitas de forma cada vez mais amiúde: estrutura da dívida pública, qualidade da receita e do gasto, obrigações governamentais de longo prazo, notadamente as previdenciárias, avaliação prospectiva de riscos de socorro ao sistema bancário e de comprometimento com corporações, bem como operações fiscais não registradas no balanço (Lopreato, 2006, p. 9). A financeirização das contas públicas define o perfil do ajuste fiscal que deve se concentrar não no aumento das receitas públicas e, sim, no corte dos gastos ou, mais especificamente, "no corte dos salários do setor público e das transferências" (Lopreato, 2006, p. 24).

$\mathrm{O}$ consenso hegemônico atribuiu papel central à política fiscal, mas, ao mesmo tempo, retirou-lhe, quase que totalmente, a autonomia. Lopreato (2006, p. 26) evidencia as razões dessa contradição aparente: ela é vista como responsável por influenciar a expectativa de rentabilidade dos títulos públicos e o comportamento das variáveis observadas pelos investidores no momento de escolher onde alocar o capital disponível, isto é, a tarefa da política fiscal é sinalizar o baixo risco das aplicações 
e dar confiança aos investidores. Dessa forma, a política fiscal se transforma, no âmbito da perspectiva mainstream e nos termos de Lopreato, em "fiadora do espaço de valorização do capital", "âncora da estabilidade macroeconômica", "farol do comportamento esperado de outras variáveis econômicas” (Lopreato, 2006, p. 7-8).

A ideia de sustentabilidade financeira intertemporal da política fiscal é, por conseguinte, um elemento importante da nova visão de disciplina fiscal que passa a ser adotada, a qual se coaduna fortemente com as demandas do mercado financeiro globalizado de minimização de riscos em suas aplicações, garantindo espaços de valorização de capital na forma da solvabilidade da dívida dos governos. Verifica-se a incorporação, na esfera das contas públicas, e especialmente da política fiscal, da mesma perspectiva que os aplicadores utilizam para seu cálculo corrente no mercado financeiro, embutindo a avaliação de risco e tornando essa a ótica prevalecente ao considerar todos os elementos referidos à atuação governamental com impacto na dívida pública.

Os componentes da política fiscal passam a estar subordinados a esse prisma hegemônico, fazendo com que as restrições financeiras à atuação dos governos assumam crescente importância. Isso pressiona os governos a darem prioridade às despesas financeiras e a elegerem os níveis de superávits fiscais como meta de curto prazo, síntese da política fiscal.

Essa nova ambiência histórica e teórica criou um mecanismo de controle indireto das finanças públicas dos governos partícipes da economia global estabelecido pelos mercados financeiros internacionalizados, intensificando as restrições do mercado em escala mundial sobre os países. Tais restrições correspondem aos níveis de abertura e liberalização dos fluxos de capital empreendidos pelos diferentes países. A introdução de indicadores fiscais nos cálculos de risco país que orientam as movimentações financeiras dos aplicadores globais equivale, na prática, a um enquadramento das políticas fiscais dos países a uma concepção ortodoxa das finanças públicas.

Todavia, apesar de sua centralidade, essa não é a única linha analítica que contribui para uma nova visão de disciplina fiscal dos governos. Uma outra, de destaque, está apoiada na abordagem da Economia do Setor Público a partir de uma concepção ainda mais estrita de disciplina fiscal. Apresenta-se, a seguir, essa linha de análise.

\subsection{A concepção de disciplina fiscal das novas visões de Economia do Setor Público}

A visão tradicional da Economia do Setor Público tornou-se inadequada para racionalizar o Estado capitalista sob a primazia da concepção neoliberal. Uma nova fundamentação teórica foi encontrada, especialmente em Buchanan, antikeynesiano 
e adepto de uma perspectiva radicalmente liberal de Finanças Públicas, resgatando a visão de que o Estado não deveria gastar mais do que arrecadava e deveria ser estritamente controlado. A visão buchaniana traz, como elemento novo, a aplicação dos supostos Neoclássicos à esfera política. Esse simples redirecionamento de foco produziu ideias de forte apelo ao senso comum referente à atuação estatal. Seu papel sancionador/justificador, no que tange à demolição do Estado keynesiano, foi inquestionável.

A mudança no quadro histórico/teórico coloca como ponto central a restrição do Estado e a sua reconstrução de forma compatível com a nova ordem mundial financeirizada. Duas escolas de pensamento respondem pelo aprofundamento das concepções de disciplina fiscal no âmbito da Economia do Setor Público: a Escolha Pública e a Nova Economia Institucional, tratadas a seguir.

\subsubsection{A escolha pública e o novo papel da disciplina fiscal}

Na Economia do Setor Público, a Escolha Pública é largamente disseminada a partir dos anos $80^{15}$, trazendo, para o centro do debate, os processos decisórios no âmbito do Estado e as motivações dos agentes políticos neles envolvidos. A novidade é a introdução da política e dos agentes políticos como elementos-chave para a explicação da atuação do Estado.

Uma frente de crítica radical e direta à visão keynesiana de Finanças Públicas ao papel que confere ao Estado e à política fiscal foi empreendida por Buchanan e Wagner (1977). Os autores questionam a visão de dívida e do déficit público keynesianos, explicitando os processos políticos envolvidos nas políticas públicas ${ }^{16}$. Segundo essa crítica, os anos de ouro do capitalismo, nos quais predominava o ativismo fiscal, seriam períodos de exceção, de desvio da "boa prática fiscal" e cujos efeitos negativos ter-se-iam manifestado, num momento posterior, na forma de estoques crescentes de dívida.

Keynes, segundo os autores, teria dado legitimidade intelectual a um regime de déficits, de inflação e de ampliação do tamanho do Estado, sendo que o déficit e a inflação contribuiriam para o crescimento do mesmo, gerando pressões inflacionárias. Ele teria transferido ao Estado a responsabilidade de manter a prosperidade da economia ao considera-lo diferente dos indivíduos, no que tange aos gastos. Para Buchanan e Wagner, os keynesianos não se preocupavam com a direção do desequilíbrio orçamentário ao longo do tempo, negando, explicitamente, que o financiamento do déficit e o endividamento trariam ônus para os contribuintes

(15) Para um panorama da Escolha Pública, ver Aguirre e Moraes (1997), Moraes (2001) e Casas Pardo (1984)

(16) Além da obra de Buchanan e Wagner (1977), que trata especificamente da questão fiscal, pode-se encontrar os fundamentos da perspectiva de governo desse autor em Buchanan e Tullock (1993) e Buchanan (1981). 
futuros, favorecendo as pessoas, na atualidade, às expensas das mesmas no futuro $^{17}$. Mas o ponto crucial, para esses autores, seria o fato de Keynes não levar em conta os processos de decisão política envolvidos na aplicação das políticas públicas. O resultado seria, segundo tal ponto de vista, uma mistura instável derivada da justaposição de prescrições econômicas pautadas no déficit, nos gastos públicos e na democracia política.

O keynesianismo é questionado, sendo responsabilizado pela quebra da regra de equilíbrio orçamentário que antes teria sido sustentada, de maneira informal, pela visão prevalecente de responsabilidade fiscal. Para os autores, o keynesianismo alteraria as restrições institucionais, segundo as quais uma política democrática operaria, dando livre expressão às tendências ao gasto excessivo dos políticos, introduzindo dois vieses: um, em direção a um grande governo e outro, em direção à inflação. Segundo essa visão, mesmo os ajustes posteriores do keynesianismo voltados para compatibilizar a ideia de orçamento equilibrado com o pleno emprego seriam insuficientes para promover uma verdadeira responsabilidade fiscal.

Seria necessário, para tanto, compatibilizar os pressupostos orientados pelo comportamento otimizador dos agentes envolvidos na política em democracias e a visão de responsabilidade fiscal pautada na noção de orçamento equilibrado e na consistência temporal. Defende, portanto, a restauração do princípio fiscal clássico, com uma definição mais estrita da atuação governamental pautada na provisão de bens e serviços. A norma fiscal quebrada deveria ser restabelecida por meio de sua formalização numa lei constitucional. Deveria ser uma regra simples e direta que oferecesse um critério claro de aderência e violação, buscando refletir e expressar os valores do cidadão. Ela restringiria a expansão orçamentária, atuando como uma regra externa e superior, restaurando as restrições fiscais por essa via, controlando o Estado e o ímpeto natural dos políticos em gastar. Aumentaria a responsabilidade global dos agentes políticos sobre os assuntos de natureza orçamentária, compatibilizando a atuação governamental e a democracia por meio do contrato constitucional.

Uma ideia basilar da Escolha Pública que se deseja destacar para a questão da disciplina fiscal é o "mercado político", seguidamente aprimorada (Affonso, 2003, p. 43-45). O mercado político seria composto de agentes (eleitores, burocratas e políticos) cujo comportamento é otimizador de determinada função-objetivo, atuando segundo os parâmetros do modelo concorrencial de mercados. Adotaria como pressupostos adicionais o caráter democrático dos processos políticos, regras políticas que possibilitariam uma participação política ampla, direta ou indireta, de todos os membros da coletividade, com o voto expressando as preferências do eleitor, orientado por um comportamento racional e maximizante, o elevado grau

(17) Esse aspecto da crítica se aplica muito mais à visão da Síntese Neoclássica do que a Keynes, que só defende o uso do déficit público para combater problemas de demanda efetiva. 
de institucionalização das regras sociais e formas preestabelecidas para atingir o consenso social aceitas pelos representantes políticos (Affonso, 2003, p. 52). Segundo essa perspectiva, o mercado político seria um elemento de disciplina por excelência que os indivíduos/eleitores exerceriam sobre o Estado, impondo-lhe suas preferências.

Um dos veios mais radicais da Escolha Pública encontra-se na noção de falhas de governo ${ }^{18}$ por meio do comportamento rent seeking ${ }^{19}$ do agente privado. Esse despenderia de recursos para viabilizar a sua participação em uma política de favorecimento criada pelo Estado, conforme Buchanan (1981, p. 214215). Essa falha seria estabelecida pela tendência do Estado em criar situações de monopólio favorecedoras dos agentes privados. Nesse perfil de políticas dirigidas, incluem-se as políticas de desenvolvimento, as políticas industriais e as políticas creditícias e fiscais de favorecimento a segmentos particulares, típicas do Estado keynesiano e desenvolvimentista e amplamente combatidas pela Escolha Pública. Sob esse prisma, impor disciplina junto ao setor público requereria atuações radicais e de desmonte, visando extinguir e evitar, no âmbito do governo, mesmo a simples menção de quaisquer políticas que privilegiassem segmentos ou setores específicos da Economia, o que, segundo essa perspectiva, minimizaria as ineficiências que o próprio Estado promoveria no mercado, ou, nos seus termos, reduziria as chamadas falhas de governo.

Com base nesse arcabouço teórico, as ações de privatizar, desregulamentar e descentralizar teriam o condão de, ao minimizar o tamanho do Estado e a sua intervenção, deslocando para o mercado o máximo de funções, estimulando a concorrência entre os níveis de governo, tanto horizontalmente quanto verticalmente, promover uma situação orçamentária equilibrada e a eficiência econômica. Seu resultado global seria o funcionamento do mercado sem amarras e o Estado mínimo.

A Escolha Pública tem sido uma importante referência teórica e ideológica para as iniciativas concretas de redução dos mecanismos típicos do Welfare State, bem como de desmonte dos Estados Desenvolvimentistas, sancionando a minimização da atuação governamental em amplas esferas e a extinção de restrições às atividades privadas, notadamente na esfera financeira. Ela foi eficiente para justificar o desmonte da visão keynesiana de Estado e questionar os fundamentos de suas políticas econômicas. Chancelou uma ampla abertura de espaço para a atuação das forças

(18) O conceito de falhas de governo na Escolha Pública é a contraface do conceito de falha de mercado na Welfare Economics. Como exemplo de falhas de governo, além do comportamento rent seeking, temos o paradoxo do voto, o poder de agenda, o logrolling, a instabilidade de maiorias e os grupos de interesse (Borsani, 2004, p. 109-119).

(19) Segundo Borsani (2004, p. 116, nota 20), o primeiro a desenvolver esse conceito foi Tullock (1959), sendo que Krueger (1974) cunhou o termo e, posteriormente, Buchanan (1981) também o desenvolveu no âmbito da Escolha Pública. 
de mercado, relegando ao Estado o papel de promotor da desregulamentação, da liberalização, da privatização e da descentralização, pautado num ambiente em que a disciplina fiscal seria reentronizada por uma regra simples, pelo Estado mínimo e pelo funcionamento do mercado político.

\subsubsection{A Nova Economia Institucional e os avanços adicionais da idéia de disciplina fiscal}

A visão liberal extrema no que tange ao Estado e ao seu papel apresentada pela Escolha Pública foi eficiente para demolir, mas incapaz de sustentar, uma reconstrução dos mesmos na ordem capitalista globalizada. As proposições dessa visão, levada às últimas consequências, passaram a apresentar um conteúdo instabilizante ao próprio capital. No plano prático, não dispunha de saídas convincentes para as crises financeiras mundiais verificadas desde meados dos anos 90. No plano teórico, a sua fundamentação, a partir do comportamento individual maximizante, era questionada enquanto elemento suficiente para promover a ordem e a explicação das ações coletivas não cooperativas. Autores demonstravam que os comportamentos egoístas não levavam a uma solução global eficiente do ponto de vista da alocação dos recursos econômicos ${ }^{20}$. Uma alternativa para esse dilema, no campo do mainstream, é dada pela Nova Economia Institucional por meio da flexibilização de alguns dos pressupostos da Escolha Pública.

Centrando-se também na escolha coletiva, bem como mantendo a fundamentação no individualismo metodológico, a Nova Economia Institucional busca arranjos eficientes para se alcançar uma situação de ótimo paretiano ou, em outras palavras, uma situação de ordem e coordenação. Conserva-se o core da Teoria Neoclássica, alterando alguns de seus pressupostos importantes considerados irrealistas e rígidos. $\mathrm{O}$ agente seria racional, mas estaria sujeito à racionalidade limitada ou a um ambiente de informação imperfeita. A ausência de informações suficientes $^{21}$ levaria ao comportamento não cooperativo, à ação antissocial e ao chamado comportamento oportunista. Esse comportamento se daria pela desconfiança do agente de que os demais perseguiriam escolhas que não maximizam o bem-estar social e teriam ganhos extras por isso. Em função dessas imperfeições, falhas de mercado generalizadas, haveria problemas nas transações entre os indivíduos, tanto no campo econômico quanto político, problemas, esses, que gerariam custos. Segundo essa perspectiva, os contratos seriam a forma institucional capaz de minimizar esse problema (Moraes, 2001, p. 50).

(20) Aspectos formalizados na Economia por Kenneth Arrow e na Ciência Política, por Mancur Olson.

(21) A assimetria de informação baseia-se em três premissas básicas: seleção adversa, caracterizada pela falta de informação, que conduz as pessoas a fazerem uma escolha errada; risco moral, caracterizado por um comportamento oportunista do interlocutor que possui mais informação; exclusão de produtos de boa qualidade, caracterizando uma situação em que o desconhecimento da qualidade de produtos propicia uma saída dos produtos de melhor qualidade do mercado tendo em vista a concorrência desleal dos produtores (Stiglitz, 2000). 
Também focada nos processos decisórios, a Nova Economia Institucional busca considerá-los não apenas no âmbito do mercado estricto senso ou do mercado político/governo, mas, sim, tendo em conta as diferentes instituições que os restringem.

Possibilitando a introdução das peculiaridades de cada contexto específico e por meio dos contratos, seriam criados incentivos e penalidades para as decisões particulares dos indivíduos participantes da escolha coletiva. Segundo essa visão, o Estado deveria utilizar seu poder de compulsão para promover institucionalidades (contratos) que levassem a ações cooperativas, redesenhando-as por meio de incentivos e punições para que a escolha coletiva se desse de forma cooperativa.

A perspectiva da Nova Economia Institucional reintroduz a necessidade de atuação ativa do Estado, ao mesmo tempo que mantém a visão negativa típica da Escolha Pública. Apesar de romper com aspectos importantes da Escolha Pública, persiste, com sua ênfase nos processos decisórios envolvidos nas políticas públicas, a preocupação com a atuação dos rent seekers e dos free riders; em outras palavras, aprofunda a concepção restritiva de política fiscal ${ }^{22}$.

O papel do Estado seria, portanto, o de gerar, de forma artificial, as institucionalidades consideradas necessárias para a fundação uma ordem pautada na economia de mercado e na democracia, reformando Estado e Mercado à luz da experiência dos países capitalistas centrais. Aplicar-se-ia, notadamente, aos países periféricos sujeitos a problemas fiscais e financeiros ao longo do processo de disseminação da globalização financeira nos anos 90 (AFFONSO, 2003, p. 91). Tal atuação compreende análises de como as instituições associadas à atuação fiscal e financeira do Estado foram criadas nesses países e como podem ser transformadas e moldadas para que gerem comportamentos cooperativos, visando conformar as políticas correlatas a rígidos padrões de disciplina fiscal, restringindo ao máximo o que consideram ser os efeitos danosos do comportamento inadequado dos agentes.

No campo estritamente fiscal, a perspectiva da Nova Economia Institucional disseminou a noção de que diferentes instituições interferem na sua conformação, dependendo do contexto em que essa política governamental está inserida $^{23}$. A promoção artificial da disciplina fiscal deveria se dar no âmbito das diversas instituições envolvidas com as políticas públicas, existentes ou a serem

(22) Oliveira (2009, p. 60-61) destaca o aspecto de a Nova Economia Institucional geralmente embutir a visão de austeridade fiscal pautada nas concepções da Macroeconomia mainstream moderna, notadamente a ideia de sustentabilidade financeira da dívida.

(23) Guardia (1999) é um exemplo de abordagem nesses moldes, tratando a política fiscal brasileira à luz das institucionalidades que elege como básicas para seu entendimento. 
criadas. O resgate do Estado como ator ativo pela Nova Economia Institucional resulta, por conseguinte, em mudanças na forma de pensar a noção de disciplina fiscal. Ela é reconstruída de maneira adequada ao novo papel que lhe deve caber no quadro mais abrangente da ordem financeirizada.

A visão buchaniana de estabelecer uma regra simples para instaurar a austeridade fiscal desdobra-se em propostas detalhadas de controle da política fiscal, impostas especialmente aos países periféricos desde fins dos anos 90. A disciplina fiscal passa a incorporar mecanismos para promover a transparência da atuação pública e controles cada vez mais específicos do funcionamento da política fiscal nos moldes das Leis de Responsabilidade Fiscal. ${ }^{24}$ Essas são normas detalhadas, voltadas para a viabilização da geração de excedentes fiscais por meio do compromisso em lei de conferir prioridade absoluta ao pagamento das despesas financeiras no âmbito interno dos Estados Nacionais. Um caso limite, mas não único, é o Brasil, cuja normatização atingiu as diferentes esferas de governo (federal, estadual e municipal) e os três poderes, adotando um verdadeiro código de controle fiscal voltado para garantir a remuneração dos detentores de dívida pública.

\section{Conclusão}

Este artigo destaca, num primeiro contexto, a centralidade e a autonomia da política fiscal no âmbito da política econômica, tendo em vista a disseminação de políticas cambiais assentadas em taxas de câmbio relativamente fixas e a prevalência de um regime monetário/financeiro disciplinado, com taxas de juros nominais e reais sob controle. A estabilidade no plano cambial e monetário possibilitava uma política fiscal mais soberana e expansionista, articulada a um ciclo longo de expansão do investimento privado cuja conjugação público/privada alçava a esfera da produção a um papel relevante na acumulação de capital. Essa ambiência institucional virtuosa, sob o ponto de vista do crescimento econômico, estimulava o gasto público e a expansão das atividades do Estado. Sua contraface foi o gradual endividamento dos governos, das empresas e das famílias, flexibilizando a restrição orçamentária desses agentes desde a expansão generalizada do crédito e a prevalência dos interesses do lado devedor da equação financeira.

Posteriormente, evidencia-se um segundo contexto que favorece os agentes privados credores do Estado e em que a política fiscal se apequena, subordinada à volatilidade das taxas de juros e de câmbio consequentes das políticas governamentais

(24) Oliva (2001) evidencia as várias experiências de implantação da Lei de Responsabilidade Fiscal (LRF), destacando, como as mais abrangentes, as da Nova Zelândia (1994), Colômbia (2000), Equador (2001) e Brasil (2000), considerando esta última, como uma das mais completas do gênero. Estas três últimas experiências ocorreram no bojo de acordos com o FMI. Outro país latino-americano com acordos junto ao FMI, que aprovou uma LRF para a esfera central, foi a Argentina em 1999. O Peru também adotou uma LRF no mesmo ano, no contexto de um empréstimo junto ao Interamerican Development Bank. 
desregulamentadoras no plano financeiro e da redução das oportunidades/taxas de rentabilidade do investimento produtivo privado. O crédito se transforma numa mercadoria em si, e as decisões de gasto das famílias, empresas e governos passam a estar condicionadas às expectativas de retorno financeiro dos investidores privados. A política fiscal se vê submetida a uma disciplina fiscal forte, cujo efeito é a financeirização de sua lógica, pressionando-a a funcionar como espaço de valorização dos capitais, bem como absorver, por meio de um ajuste fiscal estrutural, os impactos disruptivos das políticas cambial e monetária.

Este último contexto tem como consequência o esvaziamento da política fiscal de seu conteúdo potencializador no plano econômico e social, reduzindo-a a um "autismo fiscal" 25 , posto que passa a atender predominantemente a função de garantia de remuneração das aplicações em títulos da dívida pública. Pelo fato de o Estado se tornar refém do círculo vicioso de gerar recursos fiscais para honrar o serviço da dívida, dissemina-se uma noção de disciplina fiscal forte que se assenta notadamente na ideia de credibilidade da política fiscal, sustentabilidade financeira da dívida pública e nas visões de desmonte e redesenho institucionais típicas da Escolha Pública e da Nova Economia Institucional. Esta última tende a criar regulamentações crescentes à atuação do Estado, viabilizando os meios para que a financeirização avance em múltiplas frentes da atuação governamental, aprofundando os mecanismos de restrição fiscal de forma a garantir os excedentes fiscais considerados necessários à cobertura das despesas financeiras do Estado capitalista.

A disseminação, aprofundamento e complexificação da concepção de disciplina fiscal resultam na tendência a uma concepção de curto prazo das Finanças Públicas, voltada para a ampliação da carga tributária, conjugada à estagnação ou mesmo redução da qualidade do gasto público, com vistas a gerar excedentes fiscais. Esse contexto realimenta as concepções negativas de Estado, de déficit e de dívida pública, no sentido de que extraem recursos da sociedade e ao mesmo tempo reduzem os retornos que lhe proporcionam na provisão de bens públicos. Com um potencial aspecto positivo, instaura-se um ambiente que pressiona por um uso mais racional e transparente dos recursos públicos no plano corrente do orçamento governamental, mas cujo impacto favorável à sociedade depende fortemente de sua capacidade de mobilização política e de fiscalização do Estado.

Por fim, deve-se ponderar que a crise financeira internacional, que se acirrou desde a Economia Central, entre 2007 e 2008, e se manifestou novamente em 2011, tanto nos EUA quanto na Europa, não reverteu esse quadro institucional, tendo em vista ser a disciplina fiscal uma base fundamental do capitalismo financeirizado em escala mundial. O socorro governamental verificado não reverteu a desregulamentação privada nem reduziu de maneira sustentada a pressão pela

(25) Termo utilizado por Hermann (2008) para se referir ao perfil da política fiscal na atualidade. 
promoção da disciplina fiscal no âmbito do Estado capitalista. A flexibilização fiscal ocorrida foi basicamente dirigida às instituições financeiras, com baixos efeitos sobre a demanda efetiva e a retomada do crescimento econômico. Os aspectos estruturais que definem o papel da política fiscal crescentemente pautada pela austeridade fiscal e pela lógica da restrição orçamentária forte permanecem arraigados e funcionais à ordem financeirizada que prevalece, a despeito da profundidade da crise atual.

\section{Referências bibliográficas}

AFFONSO, R. de B. A. O federalismo e as teorias hegemônicas da economia do setor público na segunda metade do século XX: um balanço crítico. 2003. Tese (Doutorado em Economia)- Instituto de Economia, Universidade Estadual de Campinas, 2003.

AGUIRRE, M. B.; MORAES, M. R. de. A questão federativa no Brasil: um "estado das artes" da teoria. Revista de Economia Política, São Paulo, v. 17, n. 1, p. 121-135, jan./mar. 1997.

BAER, M. O rumo perdido: a crise fiscal e financeira do Estado brasileiro. Rio de Janeiro: Paz e Terra, 1994.

BELLUZZO, L. G. M. Finança global e ciclos de expansão. In: FIORI, J. L. (Org.). Estados e moedas no desenvolvimento das nações. 3. ed. Petrópolis: Vozes, 2000. p. 87-117.

BLANCHARD, O. J. Macroeconomia: teoria e política econômica. 3. ed. São Paulo: PrenticeHall, 2004.

Suggestions for a new set of fiscal indicators. Paris: OECD, Apr. 1990. (Working Paper, n. 79).

; CHOUAQUI, J-C.; HAGEMANN, R.; SARTOR, N. The sustainability of fiscal policy: new answers to an old question. OCDE Economic Studies, n. 15, autumn 1990.

BLEANEY, M. The rise and fall of Keynesian economics: an investigation of its contribution to capitalist development. London: Macmillan, 1985.

BORSANI, H. Relações entre política e economia: teoria da escolha pública. In: ARVATE, P. R.; BIDERMAN, C. (Org.). Economia do setor público no Brasil. Rio de Janeiro: Elsevier, p. 103-125, 2004.

BRAGA, J. C. de S. Temporalidade da riqueza: teoria da dinâmica e financeirização do capitalismo. 2000. Tese (Doutorado em Economia)-Instituto de Economia, Universidade Estadual de Campinas, 2000.

BUCHANAN, J. M.; WAGNER, R. E. Democracy in deficit: the political legacy of Lord Keynes. New York: Academic Press, 1977.

Búsqueda de las rentas y búsqueda de beneficios. In: ; McCORMICK,

R. E.; TOLLISON, R. D. El análisis económico de lo político. Madrid: Instituto de Estudios Económicos, 1984. p. 205-231. 
BUCHANAN, J.; TULLOCK, G. The calculus of consent. University of Michigan Press, 1992.

CASAS PARDO, J. Estudio introductorio. In: BUCHANAN, J. M.; McCORMICK, R. E.; TOLLISON, R. D. El análisis económico de lo político. Madrid: Instituto de Estudios Económicos, 1984. p. 17-104.

CHESNAIS, F. A mundialização financeira. São Paulo: Xamã,1998.

CLINE, W. R. United States external adjustment and the world economy. Washington: Institute of International Economics, 1989.

COUTINHO, L.; BELLUZZO, L. G. Estado, sistema financeiro e formas de manifestação da crise. In: ; BELLUZZO, L. G. Desenvolvimento capitalista no Brasil. 4. ed. Campinas: Unicamp. Instituto de Economia, 1998. v. 1, p. 11-43.

FIORI, J. L. Globalização, hegemonia e império. In: TAVARES, M. C.; FIORI, J. L. (Org.). Poder e dinheiro. Petrópolis: Vozes, 1997. p. 87-147.

GLYN, A. et al. The rise and the fall of the golden age. In: MARGLIN, S. A.; SCHOR, J. B. The golden age of capitalism. Oxford: Claredon Press, 1990.

GUARDIA, E. R. O regime fiscal brasileiro. 1999. Tese (Doutorado em Economia)Faculdade de Economia, Administração e Contabilidade, Universidade de São Paulo, 1999.

GUTTMANN, R. How credit-money shapes the economy. New York: M. E. Sharpe, 1994.

HERMANN, J. Ascensão e queda da política fiscal: de Keynes ao "autismo fiscal" dos anos 1990-2000. In: ENCONTRO NACIONAL DE ECONOMIA, 34. Disponível em: www. anpec.org.br/encontro2006/artigos/A06A152.pdf.

KEYNES, J. M. A teoria geral do emprego, do juro e da moeda; inflação e deflação. 2. ed. São Paulo: Nova Cultural, 1985. (oleção Os Economistas).

KORNAI, J. The soft budget constraint. Kyklos, Zürich, v. 39, n. 1, p. 3-30, 1986.

; MASKIN, E.; ROLAND, G. Understanding the soft budget constraint. 2004. Disponível em: <htpp://web.cenet.org.cn/upfile/80914.pdf>. Acesso em: 3 fev. 2005.

LOPREATO, F. L. C. Um olhar sobre a política fiscal recente. Economia e Sociedade, Campinas, v. 11, n. 2, p. 279-304, 2002.

. Novos tempos: política fiscal e condicionantes pós-80. Revista de Economia Contemporânea, Rio de Janeiro, v. 8, n. 1, p. 125-154, jan./jun., 2004.

O papel da política fiscal: um exame da visão convencional. Campinas: IE/ Unicamp, fev. 2006. (Texto para Discussão, n. 119).

MARRIS, S. Deficits and the dollar: the world economy at risk. Washington: Brookings Institution, 1987.

MORAES, M. R. As relações intergovernamentais na República Federal da Alemanha: uma análise econômico-institucional. São Paulo: Fundação Konrad Adenauer, 2001. 
MUSGRAVE, R. A.; MUSGRAVE, P. B. Finanças públicas: teoria e prática. São Paulo: Campus, 1980.

OATES, W. E. Toward a second-generation theory of fiscal federalism. International Tax and Public Finance, 12, 349-373, 2005. Springer Science + Business Media, Inc. Printed in the Netherlands. Disponível em: http://econweb.umd.edu/ oates/ research/2ndGenerationFiscalFederalism.pdf. Acesso em: 11 jan. 2010.

OLIVA, C. Fiscal responsibility laws: how broad should they be? Versão preliminar. In: Seminário Internacional sobre Transparência e Responsabilidade Fiscal, Rio de Janeiro, 2001. [Anais...]. Rio de Janeiro: [s. n.], 2001.

OLIVEIRA, Fabrício Augusto de. Economia e política das finanças públicas no Brasil. São Paulo: Hucitec, 2009.

PLIHON, D. A ascendência das finanças especulativas. Economia e Sociedade, Campinas, n. 5, p. 61-78, dez. 1995.

REZENDE, F. Finanças públicas. 2 ed. São Paulo: Atlas, 2001.

ROCHA, F. Déficit público e a sustentabilidade da política fiscal: teoria e aplicações. In: ARVATE, P. R.; BIDERMAN, C. (Org). Economia do setor público no Brasil. Rio de Janeiro: Elsevier, p. 493-507, 2004.

ROCHA, F. F.; GIUBERTI, A. C. Consenso político com relação à necessidade de disciplina fiscal dos estados: um estudo da Lei de Responsabilidade fiscal. In: BRASIL. Secretaria do Tesouro Nacional. Finanças públicas, 9. Prêmio Tesouro Nacional, 2004. Brasília, 2005. p. 809-837,

STIGLITZ, J. Economics of Public Sector. IE-WW NORTON, 2000.

TAVARES M. C. Ajuste e reestruturação nos países centrais: a modernização conservadora. Economia e Sociedade, Campinas, n. 1, p. 21-57, 1992.

VAN DER WEE, H. Prosperity and upheaval: the world economy, 1945-1980. London: Pelikan, 1987.

VARGAS, N. C. Estados no Brasil e o Controle Fiscal e Financeiro pela União no PósReal. 2006. 278 p. Tese (Doutorado em Economia Aplicada)-Instituto de Economia da Universidade Estadual de Campinas, Campinas, 2006. 